\title{
Pituitary adenoma presenting as the Foster-Kennedy syndrome
}

Simon Ruben, John Elston, Richard Hayward

\begin{abstract}
A 27-year-old man presented to the casualty department with visual failure. Clinically he demonstrated the Foster-Kennedy syndrome. Computed tomography revealed a large spaceoccupying lesion which was subsequently shown to be a pituitary adenoma. The literature is reviewed and possible mechanisms of the Foster-Kennedy syndrome are discussed.
\end{abstract}

The Foster-Kennedy syndrome although not a common phenomenon has been described in association with a wide variety of intracranial pathologies. We present here the first case of the Foster-Kennedy syndrome secondary to a pituitary adenoma.

The Western Ophthalmic Hospital, Marylebone Road, London

S Ruben

J Elston

The National Hospital for Neurology and

Neurosurgery, Queen

Square, London

$R$ Hayward

Correspondence to:

Simon Ruben, FRCS,

FCOphth, The Wes,

COphth, The Western

Marylebone Road, London NW1 15 YE.

Accepted for publication 26 July 1991

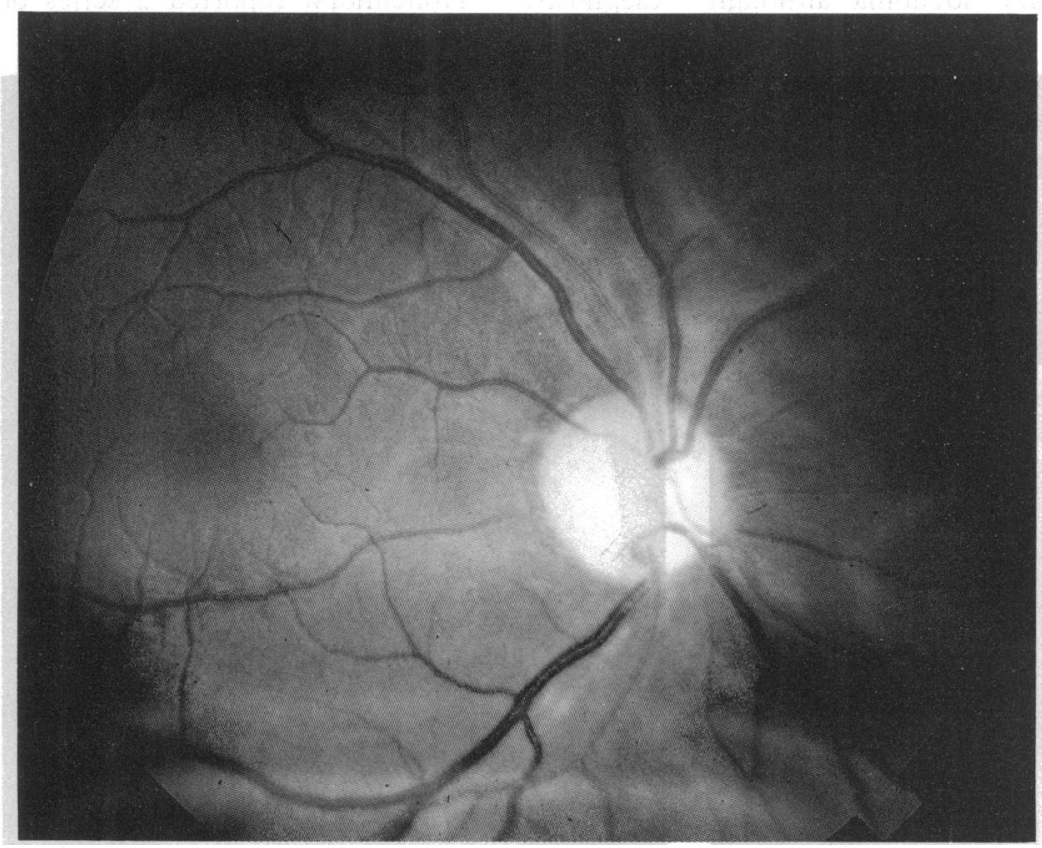

Fig $1 A$

Figure 1 Optic discs at presentation showing $(A)$ right optic atrophy and $(B)$ left papilloedema.

\section{Case report}

A 27-year-old man presented to the casualty department of an ophthalmic hospital complaining of visual failure. The vision in his right eye had been declining slowly over the preceding 4 years but over the week prior to presentation it had fallen precipitously resulting in complete blindness in this eye. The vision in the left eye had also deteriorated over the preceding week together with the onset of frontal headaches associated with nausea and vomiting. There were no other symptoms but his general practitioner

had noted the presence of a right convergent squint.

On examination he was generally well, apyrexial, alert, and orientated. Visual acuities were no perception of light on the right, hand movements on the left. There was a right relative afferent pupillary defect and fundal examination revealed optic atrophy on the right and marked papilloedema on the left (Fig 1). There was venous congestion and absent venous pulsation in both eyes. In addition he had limitation of lateral rectus function bilaterally, more pronounced on the right, and limitation of upward gaze. There were no other focal or generalised neurological signs. He was therefore diagnosed as having the Foster-Kennedy syndrome.

Computed tomography (CT) scan of the brain showed a large lobulated mass arising in the midline from near the sella turcica and extending behind the dorsum sellae into the anterior part of the posterior cranial fossa indenting the upper pons and filling the interpeduncular cysterns. It also extended upwards into the right frontal lobe distorting the ventricular cystern and obliterating the anterior horn of the lateral ventricle. There were also some areas of cystic cavitation (Fig 2).

The patient was transferred to the National Hospital for Neurology and Neurosurgery where a large right frontal tumour was excised via a frontal craniotomy. Frozen section suggested a pituitary adenoma and formal histology confirmed this and showed positive staining for prolactin. Serum prolactin was measured at 39000 megaunits/l (normal up to 480 megaunits/l). He was subsequently started on bromocriptine and by 3 weeks postoperatively the prolactin level had fallen to 600 megaunits/l.

At 4 weeks post operation the right visual acuity remained no perception of light but the left had recovered to $6 / 6$ unaided albeit with only a $5^{\circ}$ central field. The lateral rectus palsies had greatly improved. Fundal examination now revealed bilateral optic atrophy.

\section{Discussion}

The syndrome described by Foster-Kennedy in 1911, ' characterised by 'the occurrence of true retrobulbar neuritis with the formation of a central scotoma and primary optic atrophy on the side of the lesion together with concomitant papilloedema in the opposite eye', had been reported previously by Gowers ${ }^{2}$ and Paton. ${ }^{3}$ It has since been associated with a diverse selection of pathologies including frontobasal tumour, ${ }^{1+7}$ abscess of the frontal lobe, ' meningioma of the olfactory groove, ${ }^{128-11}$ falx $^{12}$ or sphenoidal wing, ${ }^{513-15}$ craniopharyngioma, ${ }^{16}$ plasmacytoma, ${ }^{17}$ nasopharyngeal angiofibroma, ${ }^{1 \times}$ 


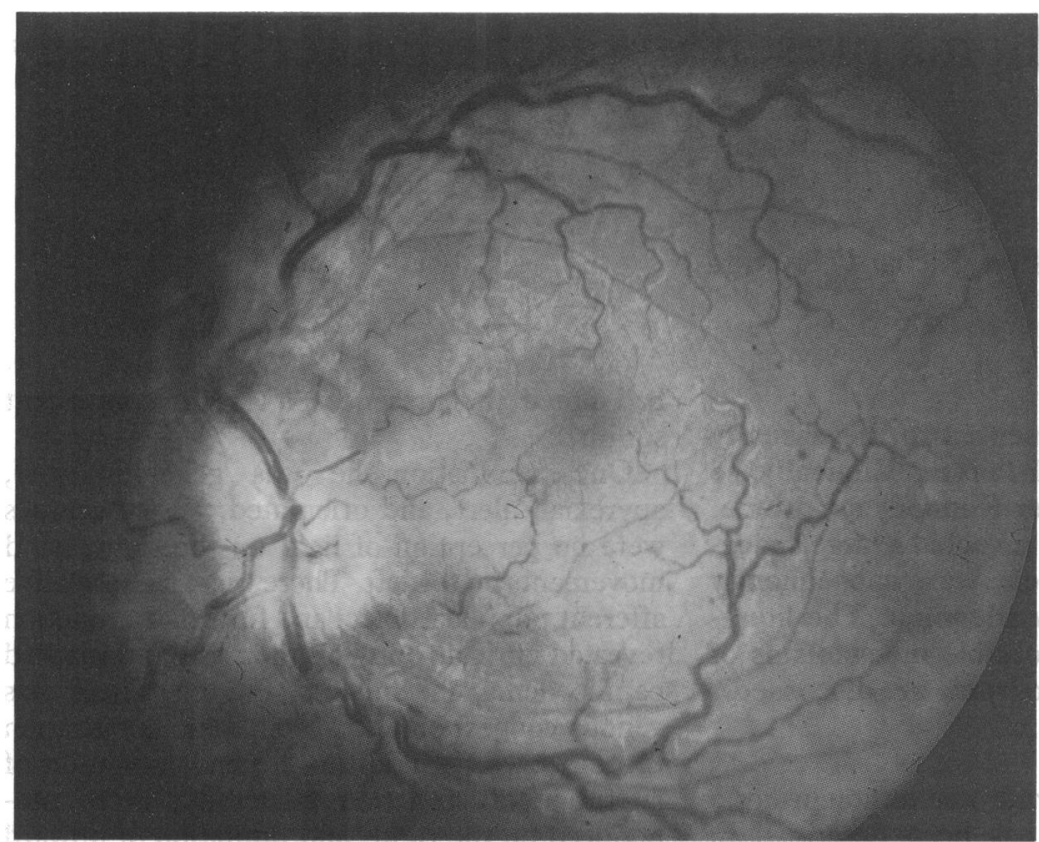

Fig $1 B$

Figure 2 CT scan at presentation showing extent of tumour. neuroblastoma, ${ }^{19}$ aneurysms, ${ }^{20}$ and other diverse intracranial lesions. ${ }^{21}$ We believe this to be the first reported case of the Foster-Kennedy syndrome occurring in conjunction with a pituitary adenoma.

The Foster-Kennedy syndrome is not a common entity. Tonnis found only 28 cases in a series of 3033 intracranial tumours, ${ }^{22}$ Von one of $46,{ }^{6}$ and Cushing seven of 29 olfactory groove meningiomas. ${ }^{7}$ This represents an overall incidence of less than $1 \%$. Only 37 cases of the Foster-Kennedy syndrome have been comall but one with evidence of an intracranial mass. ${ }^{18}$ Anosmia is often included in the syndrome but its presence has not been universally reported. ${ }^{.1}$ In none of these cases was the mass shown to be a pituitary adenoma although

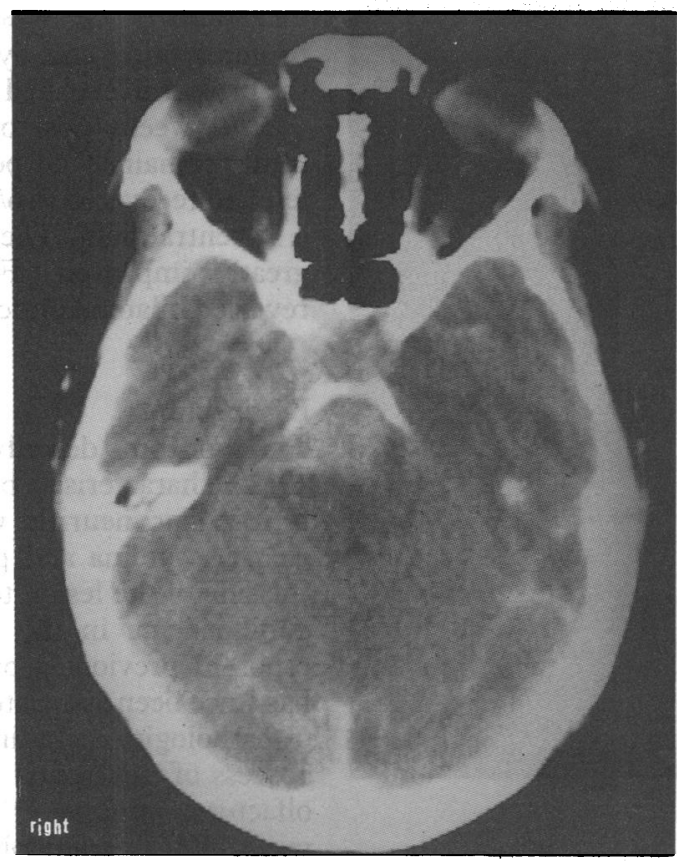

Fig $2 A$ Wowern four out of 686 frontal tumours, ${ }^{5}$ Huber pletely documented between the years 1909-89 meningiomas arising from the tuberculum sellae have been described. ${ }^{23}$ The mechanism by which the association of optic atrophy and contralateral papilloedema occurs has recently been examined and can not be attributed to a single explanation. ${ }^{18}$ The hypotheses include (1) optic nerve compression together with raised intracranial pressure, (2) bilateral optic nerve compression, and (3) chronically raised intracranial pressure without direct optic nerve compression. In this case it is difficult to exclude compression of both optic nerves from the size of the tumour. However the bulk of the tumour was on the side of the optic atrophy and there was evidence of raised intracranial pressure both clinically and on CT scan. Thus a combination of 1 and 2 seems likely and is consistent with a diagnosis of true FosterKennedy syndrome. ${ }^{124}$ Since it has now been established that the signs first described by Foster Kennedy cannot be used as 'an exact diagnostic sign' it has been suggested that this combination of clinical findings be termed the Foster-Kennedy sign. Sanders, in his study of six patients, concluded that fluorocein angiography should be performed on such cases in order to exclude local disorders at the optic disc. ${ }^{25}$ However modern imaging techniques give a far more accurate analysis of the underlying pathology and are probably the investigations of choice in the Foster-Kennedy syndrome.

This case is of interest not only in its association with the Foster-Kennedy syndrome but also in light of the declining rate of visual loss as the presenting symptom in pituitary adenomas. ${ }^{26} 27$ Although pituitary tumours are common, representing about $12 \%$ of intracranial tumours, ${ }^{26}$ the Foster-Kennedy syndrome has not previously been described as an association. In older series loss of visual field was considered an early diagnostic sign in cases of pituitary tumours, ${ }^{28}$ but more recent studies suggest that the incidence of visual abnormalities as a presenting feature is on the decline because of earlier diagnosis. ${ }^{2629}$ Hollenhorst reported a series of

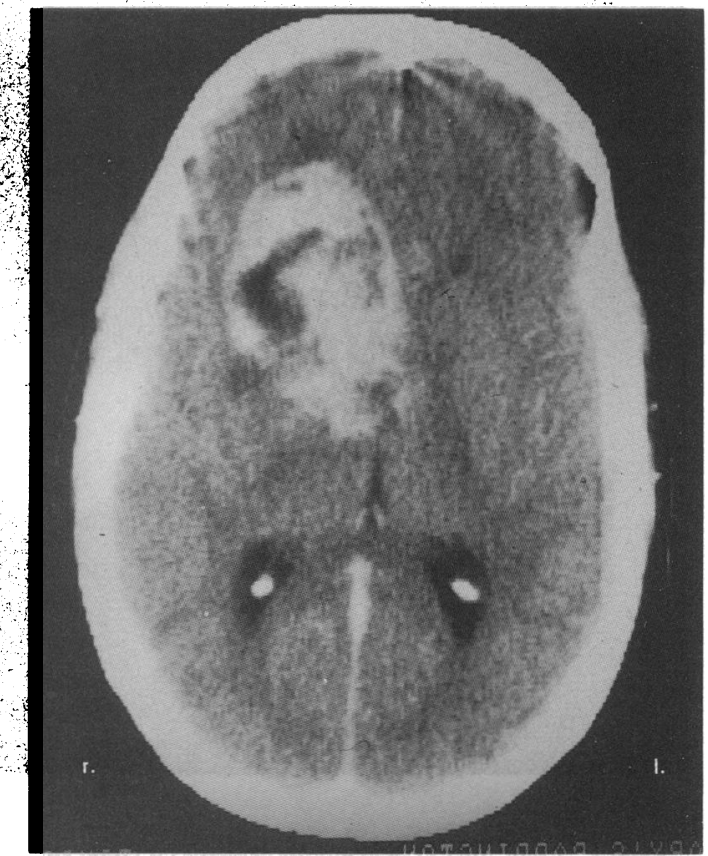

Fig $2 B$ 
1000 patients of whom $70 \%$ had visual loss, $34 \%$ optic atrophy, and 6\% extraocular muscle abnormalities. ${ }^{30}$ However in Anderson's review of 200 patients ${ }^{26}$ only $9 \%$ had visual field defects, $2 \%$ optic atrophy, and $1 \%$ extraocular muscle palsy. It is also of interest that the incidence of visual symptoms in prolactinomas was even lower, the non-secreting chromophobe adenomas having the highest incidence of visual symptoms at presentation..$^{26}$

Although the incidence of patients with pituitary tumours presenting with visual symptoms is on the decline, ophthalmologists should still be wary of patients with such complaints especially when accompanied by other symptoms such as headache.

1 Kennedy F. Retrobulbar neuritis as an exact diagnostic sign of certain tumours and abscesses in the frontal lobe. Am $\mathcal{Y} M e d$ Sci 1911; 142: 355-68.

2 Gowers WR. A lecture on a case of unilateral optic neuritis from intracranial tumour. Lancet 1909; ii: 65-8.

3 Paton L, Holmes G. The pathology of papilloedema. A histological study of 60 eyes. Brain 1911; 33: 389-432.

4 Jefferson $G$. The Doyne lecture on compression and invasion of the optic nerves and chiasm by neighbouring gliomas. Trans Ophthalmol Soc UK 1945; 65: 262-304.

5 Von Wowern F. The Foster-Kennedy syndrome. An evaluation of its diagnostic value. Acta Neurol Scand 1967; 43: 20514.

6.14.

uber A. Eye signs and symptoms and brain tumours, 3rd ed. Blodi FC, trans. St Louis: CV Mosby, 1976: 171-3.

7 Frenkel REP, Spoor TC. Visual loss and intoxication. Surv Ophthalmol 1968; 30: 391-6.

8 Cushing HC, Eisenhart MD. Meningiomas. New York: Hafner, 1962: 250-82.

9 Henderson WR. The basal meningiomas. Br $\mathcal{F}$ Surg 1938; 26: 124-63.

10 Markland ON, Chandraker KL. Foster-Kennedy syndrome in a case of olfactory groove meningioma. 7 All-India Ophthalmol Soc 1965; 13: 75-8.

11 Jarus GD, Feldon SE. Clinical and computed tomographic findings in the Foster Kennedy syndrome. Am $\mathcal{f}$ Ophthalmol 1982; 93: 317-22.

12 Neville RG, Greenblatt SH, Kollarits CR. Foster Kennedy syndrome with an optociliary vein in a patient with falx meningioma. F Clin Neuro-ophthalmol 1984; 4: 97-101.
13 Alpers BJ, Groff RA. Parasellar tumours. Arch Neurol Psychiat 1934; 31: 713 .

14 Moss JP, et al. The Foster Kennedy sign. A case with papilloedema contralateral to a shenoid wing meningioma but without apparent optic atrophy. Dis Nerv Syst 1977; 38: 62-3.

15 Bynke H. The syndrome of Foster Kennedy. Acta Ophthalmol $(K b h)$ 1958; 36: $129-40$

16 Barre JA, Kabaker J, Bruckmann. Craniopharyngiome (surtout gauche) avec enorme prolongement transfrontal (droit). Syndrome de Foster Kennedy. Troubles pyramidaux uniquement deficitaires (presentation de la piece et de radiographies). Rev Neurol 1938; 69: 511-7.

17 Coppeto JR, Monteiro ML, Collias J, et al. Foster Kennedy syndrome caused by a solitary intracranial plasmacytoma. Surg Neurol 1983; 19: 267-72.

18 Watnich RL, Trobe JD. Bilateral optic nerve compression as a mechanism for the Foster Kennedy syndrome. Ophthalmology 1989; 96: 1793-8.

19 Rakes SM, Yeatts RP, Campbell RJ. Ophthalmic manifestations of esthesioneuroblastoma. Ophthalmology 1985; 92: tions of $1749-53$.

20 Kennedy F. A further note on the diagnostic value of retrobulbar neuritis in expanding lesions of the frontal lobes: with a report of this syndrome in a case of aneurysm of the right internal carotid artery. $\mathcal{F} A M A 1916 ; 67$ : 1361-3.

21 Duke-Elder S. System of ophthalmology. Vol XII: Neuroophthalmology. London: Henry Kimpton, 1971: 294-5.

22 Tonnis $W$. Diagnostik der intrakraniellen Geschwulste. In: Olivercrona $\mathbf{H}$, Tonnis $\mathbf{W}$, eds. Handbuch der neurochirurgie. Berlin: Springer-Verlag, 1962; vol 4, pt 3:232.

23 Symon L, Rosenstein J. Surgical management of suprasellar meningioma; part 1; The influence of tumour size, duration of symptoms, and microsurgery on surgical outcome in 101 consecutive cases. F Neurosurg 1984; $61: 633-41$.

24 Sanders MD, Sennhenn RH. Differential diagnosis of unilateral optic disc oedema. Trans Ophthalmol Soc UK 1980; 100: 123 .

25 Sanders MD. The Foster Kennedy sign. Proc Roy Soc Med 1972; 65: 520-1.

26 Anderson $\mathrm{D}$, et al. Pituitary tumours and the ophthalmologist. Ophthalmology 1983; 90: 1265-70.

27 Wray SH. Neuro-ophthalmic manifestations of pituitary and parasellar lesions. Clin Neurosurg 1976; 24: 86-117.

28 Henderson WR. The pituitary adenomata: a follow up study of the surgical results in 338 cases. Br 7 Surg 1939; 26:811-921.

29 Bynke H. Pituitary adenomas with ocular manifestations. Incidence of cases and clinical findings 1946-1984. Neuroophthalmology 1986; 6: 303-11.

30 Hollenhorst RW, Young BR. Ocular manifestations produced by adenomas of the pituitary gland: analysis of 1000 cases. In: Kohler PO, Ross GT, eds. Diagnosis and treatment of In: Kohler PO, Ross GT, eds. Diagnosis and treatment of pituitary tumours. (International Congress 